\title{
LA VALORIZACIÓN DEL PATRIMONIO CULTURAL EN EL CENTRO HISTÓRICO DE ZACATECAS, MÉXICO
}

\author{
THE VALUATION OF THE CULTURAL HERITAGE IN THE HISTORICAL \\ CENTER OF ZACATECAS, MEXICO
}

\author{
Mariana Rubí Raygoza Castro \\ Universidad Autónoma de Zacatecas, México
}

\section{RESUMEN}

El objetivo de este trabajo es analizar el proceso de mercantilización, es decir, la puesta en valor del patrimonio cultural ubicado en el Centro Histórico de Zacatecas (CHZ), desde su nombramiento como Patrimonio de la Humanidad en 1993 por UNESCO. Al adquirir dicha denominación se han gestado dinámicas de explotación a favor de algunos individuos y grupos de interés, generando con ello el despojo de los espacios públicos, la elitización del consumo cultural en los habitantes, la especulación inmobiliaria, y la reasignación rentista en el uso de suelo. Como resultado, se observa un proceso de transformación para el servicio turístico en beneficio de una élite en el poder y no de los propios habitantes. Lo evidencia el análisis de datos estadísticos, mapas y referencias bibliográficas.

Palabras clave: valorización, patrimonio cultural, centro histórico, mercantilización, renta turística.

\begin{abstract}
The aim of this article is to analyze the commercialization process, that is, the enhancement of the cultural heritage located in the Historic Center of Zacatecas (CHZ), since its appointment as a World Heritage Site in 1993 by UNESCO. By acquiring this category, exploitation dynamics have been developed in favor of some individuals and interest groups, thereby generating the dispossession of public spaces, the elitization of cultural consumption in the inhabitants, real estate speculation, and the revenue reallocation in the use of the land. As a result, a transformation process is observed for the tourist service for the benefit of an elite in power and not of the inhabitants themselves. This is evidenced by the analysis of statistical data, maps and bibliographic references.
\end{abstract}

Keywords: valuation, cultural heritage, historical center, commodification, tourist revenue.

Este es un artículo Open Access bajo la licencia Creative Commons AtribuciónNoComercial-Compartirlgual 4.0

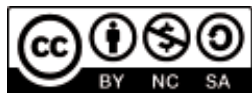




\section{Introducción}

La ciudad de Zacatecas está ubicada en la región centro-norte de México; fundada en el siglo XVI, su traza urbana corresponde a una ciudad entre cañadas y, de alguna forma, su planeación urbana está adaptada al crecimiento que no se tenía previsto en su fundación. Sin embargo, es debido a su originalidad en el asentamiento urbano y a la conservación de su arquitectura que el Centro Histórico de Zacatecas es considerado por UNESCO (Organización de las Naciones Unidas para la Educación, la Ciencia y la Cultura) como Patrimonio de la Humanidad. Actualmente, esta designación atrae la atención de visitantes interesados en acceder a la riqueza histórico-cultural de una de las ciudades coloniales de México.

La nomenclatura de la UNESCO ha sido el mecanismo para mercantilizar al patrimonio cultural de Zacatecas. Su operación depende de la creación de una zona de enclave que hace posible la obtención de una renta turística. Se trata, en lo fundamental, de la puesta en valor de los atractivos histórico-culturales que constituyen el patrimonio cultural. Los efectos sociales, laborales, urbanos y las disputas entre los grupos de interés plantean la necesidad de profundizar en el estudio de la privatización del patrimonio y sus símbolos.

\section{Centro Histórico de Zacatecas como Patrimonio Cultural de la Humanidad}

La ciudad de Zacatecas se encuentra ubicada en la parte centro-sur del estado de Zacatecas en México. Fue fundada en 1546, su traza urbana corresponde a una ciudad entre cañadas. En época novohispana adquiere dos nombramientos, en 1548 fue declarada «Real de Minas de Nuestra Señora de los Zacatecas» y, posteriormente, en 1588 adquirió el título real por mandato del rey de España Felipe II como la «Muy Noble y Muy Leal Ciudad de Zacatecas» por todos los beneficios de la extracción de minas (Bakewell, 1997).

La traza del centro histórico corresponde a las adaptaciones posteriores sobre el accidentado terreno, debido a los asentamientos en la zona urbana y a la migración en masa para extraer los minerales. Por esta causa prospera una ciudad edificada y se incrementa la instalación de servicios, logrando su mayor apogeo en los siglos XVI y XVII (UNESCO, s. f.), que la convierte en la segunda ciudad más importante de la Nueva España por los bienes de la extracción de plata (González, 2005).

Es por esa particular traza urbana y la conservación de los edificios que el Centro Histórico de Zacatecas fue nombrado el 11 de diciembre de 1993 Patrimonio Cultural de la Humanidad por la UNESCO en la categoría de ciudad histórica (Figura 1). Otro organismo que también intervino en dicho nombramiento fue ICOMOS (Comité Internacional de Monumentos y Sitios), por gestiones de algunos miembros de la élite zacatecana interesados en el proyecto de la rentabilización del centro histórico. Más tarde, también se logra otro nombramiento por UNESCO dentro de la categoría de itinerario cultural en 2010, que abarca trece puntos distintos a lo largo del estado de Zacatecas conocido como «Camino Real de Tierra Adentro».

Estos nombramientos dieron origen a posteriores acciones principalmente del gobierno, con el fin de abarcar espacios para el disfrute turístico, que planteaba mejorar el crecimiento económico contando con la aceptación social. Actualmente estos nombramientos atraen la atención de los visitantes a la ciudad -y también de inversionistas- por ser un destino turístico como una de las ciudades de origen colonial en México. 
El proyecto turístico cultural se ha gestado con diversas formas de articulación entre recursos públicos y de inversión privada, a partir del nombramiento de 1993, orientados hacia la mercantilización del patrimonio cultural arquitectónico y el soporte de una infraestructura cultural, todo ello, con el propósito de generar una fuente de ganancias basadas en la renta turística, la cual es apropiada por un complejo empresarial privado que constituye una transferencia de valor del trabajo al capital, del sector público al privado y de bienes comunes a intereses corporativos.

\section{Figura 1 \\ Límites del Centro Histórico de Zacatecas declarado como Patrimonio Cultural de la Humanidad por la UNESCO}

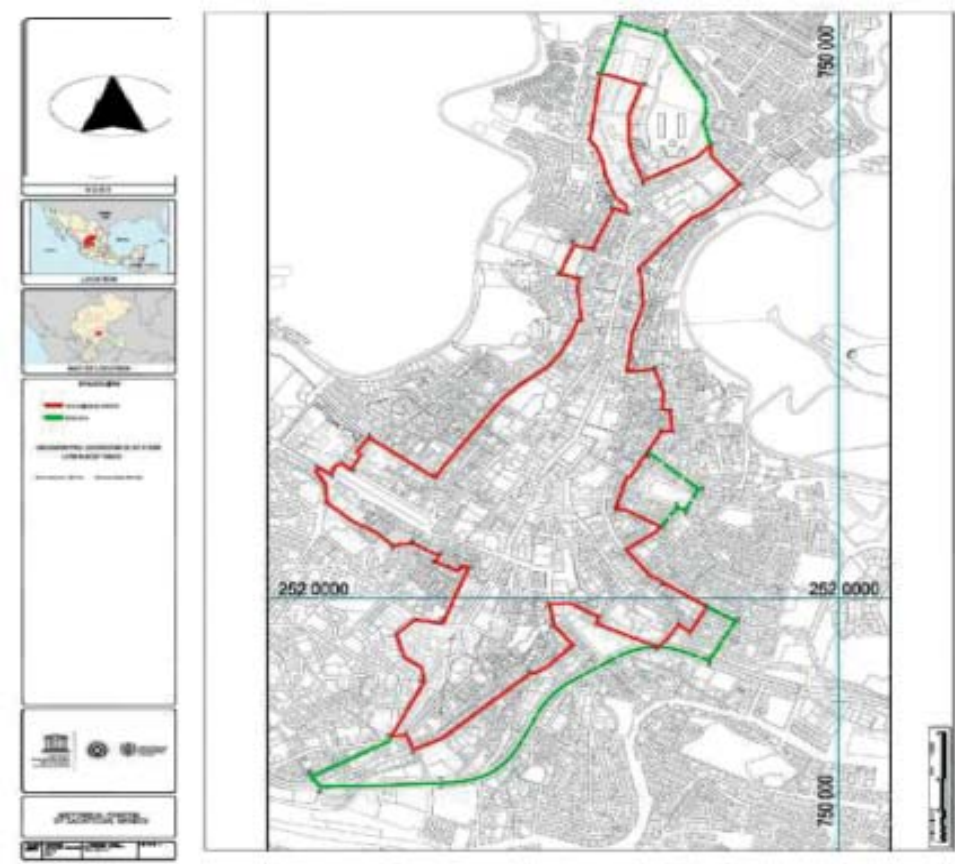

Nota. UNESCO. Documento List//. ${ }^{\circ}$ 676. Zacatecas, 2013. https://whc.unesco.org/en/list/676/ multiple=1\&unique_number=800 consultado y editado el 10 de diciembre de 2019.

\section{Turismo cultural}

Si bien el turismo se ha convertido en un sector económico relevante, su evolución como actividad de ocio también ha tenido cambios. De ello da cuenta el hecho de que, en el caso del turismo cultural, la prioridad se ha centrado en la búsqueda de experimentar las prácticas «auténticas» de las comunidades y localidades de destino. Lo cultural puede ser creado y recreado (Benjamin, 1989) en detrimento de lo que es propiamente cultural, pero esta reproducción masiva, y la escenificación que implica, genera fenómenos sociales y urbanos de diversa índole:

El turista actual ya no muestra atención por elementos consolidados -patrimoniales, culturales, etc.-, que se han ubicado tradicionalmente en lo que se ha venido en denominar la burbuja turística (Judd, 1999), sino que huye de la misma en búsqueda de lo que considera auténtico. Demanda y producción 
se dan la mano en este ejemplo de superación de anteriores límites internos. Además, las aproximaciones a fenómenos urbanos como la gentrificación o los problemas de transporte y movilidad han quedado, en cierta medida, obsoletas ya que es imposible diferenciar los efectos generados por la presencia constante y decidida de consumidores de espacios turísticos, de aquellas otras dinámicas originadas por sujetos que desembarcaban en ciertos barrios en busca de experiencias urbanas. (Marcús, Mansilla, Boy, Yanes y Aricó, 2019, p. 11)

Una de las modalidades de organización territorial que caracteriza actualmente a los destinos turísticos en cualquier país del mundo es su condición de espacio; con características únicas tanto para los visitantes como para quienes invierten en su infraestructura, es decir, en el turismo se abren oportunidades como destino de nuevas fuentes de inversión. Construir un espacio cultural tiene implicaciones como las de cualquier otro escenario: hay que establecer una delimitación de lo que pertenece o no a las tradiciones, lo que simboliza o no a las prácticas y, en general, construir un espacio que permita vivir una experiencia única.

Una experiencia de esa naturaleza es la que busca el turista consumidor de la cultura y, dado que la cultura es un patrimonio intangible, entonces hay que establecer delimitaciones físicas o virtuales para su goce. Esa es la razón que explica la necesidad de una zona de enclave, que una vez delimitada puede generar una renta extraordinaria por el hecho de poseer atributos únicos que, a diferencia de la renta absoluta en Marx, no proviene de la riqueza del suelo, sino de la condición excepcional que la mercadotecnia le atribuye.

La renta turística se convierte así en un nuevo terreno para la valorización del capital. En su búsqueda confluyen capitales internacionales, nacionales y locales atraídos por esa renta, pero su obtención no solo depende de los atributos asignados a la cultura y a las tradiciones locales, sino a la capacidad de obtener plusvalía extraordinaria de la mano de obra, lo que explica las condiciones de precarización que son comunes a la gran mayoría de los centros turísticos, en especial en los países periféricos.

También, en este proceso de búsqueda de nuevos inversionistas, los gobiernos abren crecientes posibilidades de acceso a los capitales nacionales y extranjeros, con el estímulo de reducir los requerimientos en materia de regulaciones ambientales, laborales, de asentamientos humanos -asumiendo los costos de la urbanización- y de otros que son igualmente importantes para el crecimiento ordenado de dichos enclaves, en especial porque su dinámica genera efectos sobre el equilibrio con el entorno físico y social que le rodea.

Estas consideraciones son relevantes a la luz de la importancia que ha ganado el turismo cultural. Desprovisto de los males que se atribuyen al turismo de masas -hacinamiento, deterioro ambiental y descomposición social, por ejemplo- el turismo cultural es más «limpio», pero conlleva su propia carga de problemas en los mismos espacios. La crítica a los enfoques neoliberales y tradicionales sobre el turismo se constituye en la base sobre la cual se debe profundizar en los problemas que acarrea el desarrollo del turismo en el esquema económico del capitalismo contemporáneo. De ahí la pertinencia de abordar al turismo cultural dentro de su propia connotación fetichizada: la propia cultura se desdibuja para no ser lo que es y convertirse en lo que el turista quiere que sea. Una de las vertientes que analizan críticamente este proceso se encuentra en la crítica de la modernidad (Munk, 2011), donde se estudia la cultura económica del capitalismo contemporáneo que mercantiliza no solo el trabajo, 
la tierra y el dinero, sino la cultura, los elementos de la vida cotidiana y de la reproducción (Márquez y Delgado, 2011).

El turismo cultural dentro de la modernidad capitalista da cuenta del proyecto turístico como una modalidad de la renta turística y, en específico, de la valorización del patrimonio cultural como un tema relevante para los estudios del desarrollo, la cultura, el turismo y el desarrollo.

\section{La renta turística}

El concepto de renta tiene diversas connotaciones que se basan en el hecho de que se sustenta en la propiedad de un recurso natural que tiene ciertas cualidades que lo hacen productivo. En lo fundamental se refiere a la propiedad de una parte del planeta que no fue producto del trabajo humano y en el capitalismo supone la separación entre el propietario de la tierra y el capitalista (Marx, 1991, p. 1000); la renta forma parte de la plusvalía que se distribuye entre las clases económico-sociales distintas a los medios de producción que se utilizan en la esfera productiva, pero es una de las modalidades en las que se distribuye la riqueza social (otros son la ganancia y los salarios, por señalar las formas de distribución del plusvalor). La renta es un beneficio derivado de la propiedad privada sobre la tierra, que posteriormente amplía sus alcances a otros ámbitos como lo crediticio. Detrás de este concepto subyace el hecho de que la renta es un «premio» a la propiedad de ciertos bienes o servicios en los que su propietario no participa directamente en el proceso de producción. En este punto cabe hacer una distinción analítica fundamental entre la renta y la ganancia extraordinaria: la primera es resultado de la propiedad privada de un recurso natural con cualidades excepcionales; la segunda, es producto temporal de la competencia: «la renta siempre es un excedente sobre la ganancia» (Marx, 1991, p. 816).

Ampliando sus alcances analíticos, la renta «es la retribución del poder de monopolio de la propiedad privada de algún bien crucial, desde la tierra hasta una patente, que resulta por tanto el punto de partida y de llegada de toda actividad capitalista» (Harvey, 2013, pp. 143-144). En este sentido, las nuevas formas de mercantilización que operan en el circuito de la renta incluyen bienes comunes, cultura, estética, historia y tradición; el problema ahora para el gran capital es encontrar las maneras de integrar, subsumir, mercantilizar y monetizar en sus diferencias como para extraer de ellos rentas de monopolio (Harvey, 2013).

Dado el carácter único que se otorga al patrimonio histórico-cultural, el turismo fincado en este tipo de patrimonio obtiene una renta turística excepcional, es decir, una renta por arriba de la ganancia, una ganancia media más una plusganancia que se alcanza en un espacio económico preferente reconvertido en economía de enclave, controlado por uno o varios capitalistas especializados en los servicios turísticos y culturales.

El llamado patrimonio cultural es convertido en mercancía, servicios turísticos y culturales, ofrecidos a consumidores solventes, turistas y lugareños, es decir, se pone en valor, se mercantiliza. La ganancia extraordinaria que obtiene el capitalista no se deriva de las propiedades inherentes al patrimonio -como sucede en la renta absoluta en el caso de la tierra-, sino de características que se le atribuyen basados en una designación que otorga un ente internacional que acredita la unicidad del patrimonio. En ausencia de dicha designación, el «valor» del patrimonio sería totalmente distinto y adquiriría sentido siempre y cuando los visitantes pudieran reproducir 
las prácticas, las tradiciones y las costumbres del lugar en cuestión; en vez de ello, se compran todos esos atributos. En realidad, el patrimonio cultural se desdibuja y se fetichiza, se transforma en una amalgama entre lo que el turista quiere ver y lo que el espectáculo mercantil-capitalista quiere ofrecerle.

Estas dinámicas de la rentabilización turística se generalizan al amparo de la implantación del modelo neoliberal, que busca las formas de liberalizar el capital mediante la apropiación y transferencia de ganancia que, en los proyectos turísticos, implica ofrecer a la venta cualquier producto o servicio susceptible de ser comercializado y mercantilizado. No es casual que los cambios acontecidos en el sector turístico de Zacatecas -en sus dimensiones patrimonial y cultural- se hayan observado a principio de los ochenta y se hayan consolidado en 1993 en plena etapa de expansión de las medidas aperturistas propias de neoliberalismo en sus dos periodos: el primero, relativo al ajuste del gasto y el retraimiento del Estado en la economía y, el segundo, vinculado con la eliminación de las regulaciones para el ingreso de capitales en sus modalidades financieras y rentistas, que también abarcan a los sectores extractivistas.

\section{El Centro Histórico de Zacatecas y su configuración urbana de población y vivienda}

Es de notar que los centros históricos muestran una problemática específica por las características que van presentando en sus transformaciones donde dejan de ser el centro de una población activa y arraigada en sus costumbres. Se pone de lado la identidad de generaciones anteriores al despoblar la zona centro por no presentar condiciones idóneas para la habitabilidad (por el paso del tiempo algunos inmuebles tienen graves deterioros en su estructura). Es el caso del Centro Histórico de Zacatecas que, en 2016, contaba con 1630 viviendas desocupadas (Covarrubias, 2016), algunas de las razones: problemas de abastecimiento de agua; cambio de uso de suelo, del uso habitacional al comercial en sus inmuebles; alto costo de renta a casa habitación en comparación con la periferia; congestión vial y falta de espacios para estacionamiento; además de la descentralización de servicios como escuelas, oficinas y servicios de salud.

Analizando el modelo de ciudad funcional, se determina que hay claras divisiones de sus centralidades (Sepúlveda, 2017); por un lado, la centralidad urbana, y por otro, la centralidad histórica, en el supuesto de que se decida dar prioridad a esta última, se desplazan las nuevas formas de un centro urbano tradicional (crecimiento y descentralización), antes se contaban con oficinas centrales de gobierno y económicas, incluso actividades sociales, así como actividades político-administrativas pero en la nueva modalidad generan en la periferia nuevas centralidades.

La descentralización de los servicios y oficinas administrativas del Centro Histórico de Zacatecas generó su disgregación y/o despoblamiento a partir de los años noventa del siglo XX (ver Tabla 1). Para ampliar la descentralización en el ámbito político-administrativo se construyó una Ciudad Administrativa en 2010, donde actualmente se encuentran, en su mayoría, las oficinas de gobierno. 
Tabla 1

Población total de Zacatecas, por municipio, ciudad y centro histórico. Periodo 1980-2010

\begin{tabular}{lcccc}
\hline & 1980 & 1990 & 2000 & 2010 \\
\hline Municipio & 88807 & 108556 & 123899 & 138176 \\
Ciudad de Zacatecas & 80088 & 100051 & 113947 & 129011 \\
Centro histórico & 39938 & 41111 & 33926 & 34865 \\
\hline
\end{tabular}

Nota. Basado en INEGI, Censo de Población y Vivienda 1980, 1990, 2000 y 2010.

También fue el caso de la transición económica que las zonas industriales y las grandes empresas se asentaran en los municipios vecinos de la zona central de Zacatecas por cuestiones de espacio, permisos y equipamiento. En el ámbito social, se detecta la creación de nuevos fraccionamientos en la zona conurbada y en el municipio de Guadalupe, que convierten a esta última en una «ciudad dormitorio» (González, 2014) por encontrarse la mayoría de los servicios de salud, educación y administrativos en la zona de Zacatecas, también se crean zonas de esparcimiento cultural y deportivo en la zona conurbada. Toda esta dinámica ha desplazado a la población de bajos recursos de la zona centro hacia la periferia del centro histórico donde se vienen generando nuevos complejos urbanos.

El perfil económico del centro histórico es fundamentalmente comercial, aunque también representa el punto focal en la estrategia de turismo cultural para atraer inversión pública y privada. Este carácter dual no ha permitido materializar las expectativas de crecimiento económico que desde la perspectiva oficial debería generar el turismo cultural, ya que es frecuente que los intereses comerciales se vean enfrentados con los relativos al turismo cultural. Ello se constata al observar que el gasto promedio de los turistas se ha mantenido por debajo de los 3000 pesos por estancia (González, 2014, p. 119) en los años que han pasado desde que se designó a Zacatecas como destino turístico (1986), ni de las más de dos décadas desde que se le designó por la UNESCO como Patrimonio Cultural de la Humanidad (1993).

Los sectores que son beneficiados con el proyecto turístico son el complejo empresarial, que se subdivide a la vez en subsector inmobiliario (encargado de la compraventa y renta), las empresas hoteleras y restauranteras, las agencias de viaje, los locales de diversión nocturna, entre otros. Desde el sector inmobiliario existe en el Centro Histórico de Zacatecas el cambio de uso del suelo, el incremento de las rentas, y la población desplazada. El gobierno, dentro de sus administraciones municipales, ha elaborado planes de manejo del centro histórico que no se han logrado llevar a cabo porque dependen sus gestiones de una corta temporalidad que se renuevan cada tres años. En ellos se proyecta un uso adecuado de la ocupación de inmuebles y la normativa sobre las posibles contingencias que se podrían presentar, por ejemplo, al manejar carga excesiva y manejo de desechos.

Las características de la vivienda en el centro histórico tienen como constante la degradación del paso de los años, el uso y falta de mantenimiento; se habla de un total de poco más de 10000 viviendas de uso habitacional en los polígonos centrales (Covarrubias, 2016); en promedio se cuentan 40 viviendas por hectárea. Analizando el mapa (Figura 2) se puede observar el desplazamiento de la población hacia la periferia, en la parte central se asocian los eventos de la actividad turística y en el censo de población de 2010 se proyectan manzanas sin 
habitantes. Se estima que habitan de uno a 100 habitantes por hectárea, y de 101 a 300 en la zona central en promedio (Programa Parcial del Centro Histórico, 2016).

\section{Figura 2}

Densidad de vivienda en el Centro histórico de Zacatecas, 1990-2010

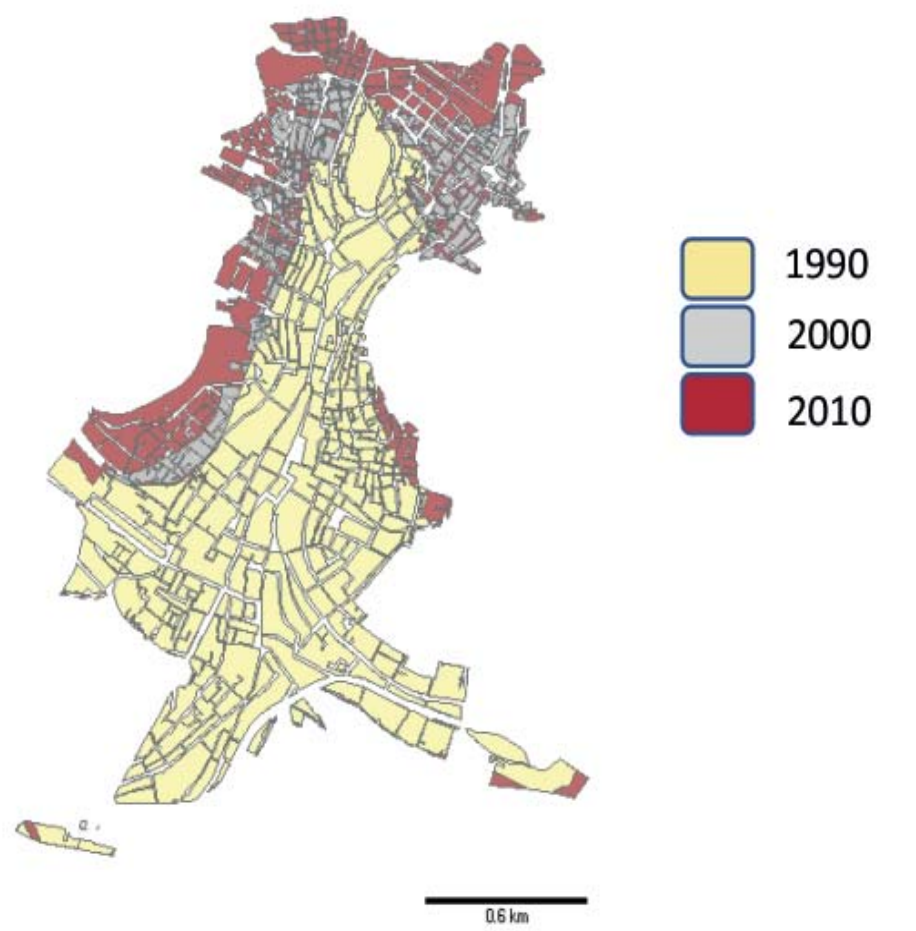

Nota. Datos del Instituto Nacional de Estadística y Geografía (INEGI). Mapa Digital de Escritorio 6.3 con la cartografía urbana de Zacatecas, 1990-2010.

\section{La valorización del patrimonio cultural}

Desde su gestación se observa que el turismo en Zacatecas es de índole cultural. Por sus características físicas y geográficas la entidad se encuentra lejos de los destinos de playa y grandes urbes, por lo tanto, se apostó por valorizar el patrimonio cultural, apoyados en la herencia histórica que procedió de la minería en mayor parte del territorio y el acervo cultural que se formó paulatinamente.

En el estado de Zacatecas el proyecto turístico se apoya en la estrategia de valorización (o mercantilización) del patrimonio cultural, esto se debe a que el capital está organizado en cadenas de valor que precarizan el trabajo, se apropian de los espacios públicos, además reciben apoyos económicos de lo público y privado, articulan paquetes turísticos, disfrute de festivales y ferias con la intención de apropiarse de la renta turística alrededor de lo que deriva del turismo cultural.

La tendencia por apropiarse de un espacio público con declaratoria patrimonial es usual en los centros históricos (Sepúlveda, 2017), ya que los intereses económicos y políticos parten de las gestiones de gobierno y de la 
inversión privada por expandir su capital hacia el uso y disfrute de los espacios y eventos turísticos para el beneficio de las élites de poder (González, 2014), trayendo como consecuencia el desplazamiento de la población que cada vez encuentra menos accesible el espacio en términos social-económico que ocupa en el centro histórico. El énfasis en obtener una renta excepcional se manifiesta en la creación de infraestructura para dar cabida a los visitantes. Este proceso es común a la mayoría de las ciudades patrimonio, aunque los resultados obtenidos no siempre corresponden con la magnitud de los capitales y en general con el gasto realizado. Como se observa en la Tabla 2 los niveles de la ocupación y la estadía de los visitantes son relativamente bajos en todo el país. En el caso de Zacatecas es baja en términos generales, no obstante situarse por encima de la media de los principales indicadores de ocupación y estancia, a partir de las declaratorias de la UNESCO.

\section{Tabla 2}

Principales ciudades Patrimonio de la Humanidad en México, indicadores de ocupación y estancia de turistas, 1992-2010

\begin{tabular}{|c|c|c|c|c|c|c|c|c|c|c|}
\hline \multirow{2}{*}{\multicolumn{2}{|c|}{ Ciudad }} & \multirow[b]{2}{*}{$\begin{array}{c}\text { Año de } \\
\text { Declaración } \\
\text { como } \\
\text { Patrimonio de la } \\
\text { Humanidad }\end{array}$} & \multicolumn{4}{|c|}{1992} & \multicolumn{4}{|c|}{2010} \\
\hline & & & $\begin{array}{c}\text { Cuartos } \\
\text { disponibles }\end{array}$ & $\begin{array}{l}\text { Cuartos } \\
\text { ocupados }\end{array}$ & $\begin{array}{c}\text { Porcentaje } \\
\text { de ocupación } \\
\text { por año }\end{array}$ & $\begin{array}{c}\text { Estadía } \\
\text { promedio }\end{array}$ & $\begin{array}{c}\text { Cuartos } \\
\text { disponibles }\end{array}$ & $\begin{array}{l}\text { Cuartos } \\
\text { ocupados }\end{array}$ & $\begin{array}{c}\text { Porcentaje } \\
\text { de ocupación } \\
\text { por año }\end{array}$ & $\begin{array}{c}\text { Estadía } \\
\text { promedio }\end{array}$ \\
\hline 1. & Zacatecas & 1993 y 2010 & 406,313 & 189,715 & $46.7 \%$ & 1.3 & $1,079,135$ & 465,579 & $43.1 \%$ & 1.8 \\
\hline 2. & Aguascalientes & 2010 & 565,744 & 278,533 & $49.2 \%$ & 1.9 & $1,457,276$ & 495,148 & $34.0 \%$ & 1.8 \\
\hline 3. & $\begin{array}{l}\text { San Miguel de } \\
\text { Allende }\end{array}$ & 2008 & 299,660 & 97,012 & $32.4 \%$ & 2.0 & 538,851 & 181,786 & $33.7 \%$ & 1.8 \\
\hline 4. & Guanajuato & 1988 & 640,278 & 239,651 & $37.4 \%$ & 1.5 & 961,811 & 383,253 & $39.8 \%$ & 1.8 \\
\hline 5. & Puebla & 1987 & 961,980 & 491,613 & $51.1 \%$ & 1.7 & $1,999,302$ & $1,059,158$ & $53.0 \%$ & 1.4 \\
\hline 6. & Durango & 2010 & 475,890 & 288,662 & $60.7 \%$ & 1.8 & 560,352 & 258,590 & $46.1 \%$ & 1.5 \\
\hline 7. & Querétaro & 1996 & 697,363 & 431,514 & $61.9 \%$ & 1.6 & $1,522,407$ & 908,175 & $59.7 \%$ & 1.7 \\
\hline 8. & Campeche & 1999 & 261,893 & 117,831 & $45.0 \%$ & 1.3 & 488,362 & 257,699 & $52.8 \%$ & 1.6 \\
\hline & San Luis Potosi & 2010 & 860,851 & 402,963 & $46.8 \%$ & 1.7 & $1,439,734$ & 688,742 & $47.8 \%$ & 1.5 \\
\hline 10. & Oaxaca & 1987 & 995,953 & 470,841 & $47.3 \%$ & 1.8 & $1,909,062$ & 756,446 & $39.6 \%$ & 1.7 \\
\hline 11. & Morelia & 1991 & 965,099 & 523,039 & $54.2 \%$ & 1.6 & $1,426,717$ & 640,700 & $44.9 \%$ & 1.5 \\
\hline
\end{tabular}

Nota. Compendio Estadístico del Turismo en México 2018, DATATUR. https://www.datatur.sectur.gob.mx/SitePages/CompendioEstadistico.aspx

El Estado busca legitimarse a través de las declaratorias y los nombramientos para autentificarse como espacios «únicos» (Harvey, 2013) y a partir del respaldo de ley se busca la expansión de inversiones o financiamientos que serán gestionados directamente por el gobierno, creando una serie de condiciones para establecer comercios, espacios y eventos públicos para el disfrute de una determinada audiencia con poder adquisitivo, en una zona predominante, generando la mercantilización del patrimonio cultural.

En su mayoría los centros históricos como destinos turísticos se han posicionado en las preferencias de los visitantes, y es que, para las perspectivas del consumismo, la cultura se ha convertido en mercancía que, analizada desde la perspectiva de la sociedad del consumo, del espectáculo y la cultura se puede derivar el verdadero actuar de los distintos agentes que intervienen en el desarrollo.

Las actividades sociales, culturales y comerciales son varias en las que destaca el aprovechamiento de los espacios públicos que están al servicio del turismo, de aquí deriva a su vez el aprovechamiento de los espacios 
para la creación de espectáculos al aire libre que permiten diseñar un discurso de identidad creada o manipulada para la formación de públicos consumistas en la modernidad neoliberal, en Zacatecas destacan los edificios de relevancia arquitectónica (ver Figura 3 y 4).

\section{Figura 3}

Calles del Centro Histórico de Zacatecas, (A) calle Tacuba, (B) avenida Hidalgo
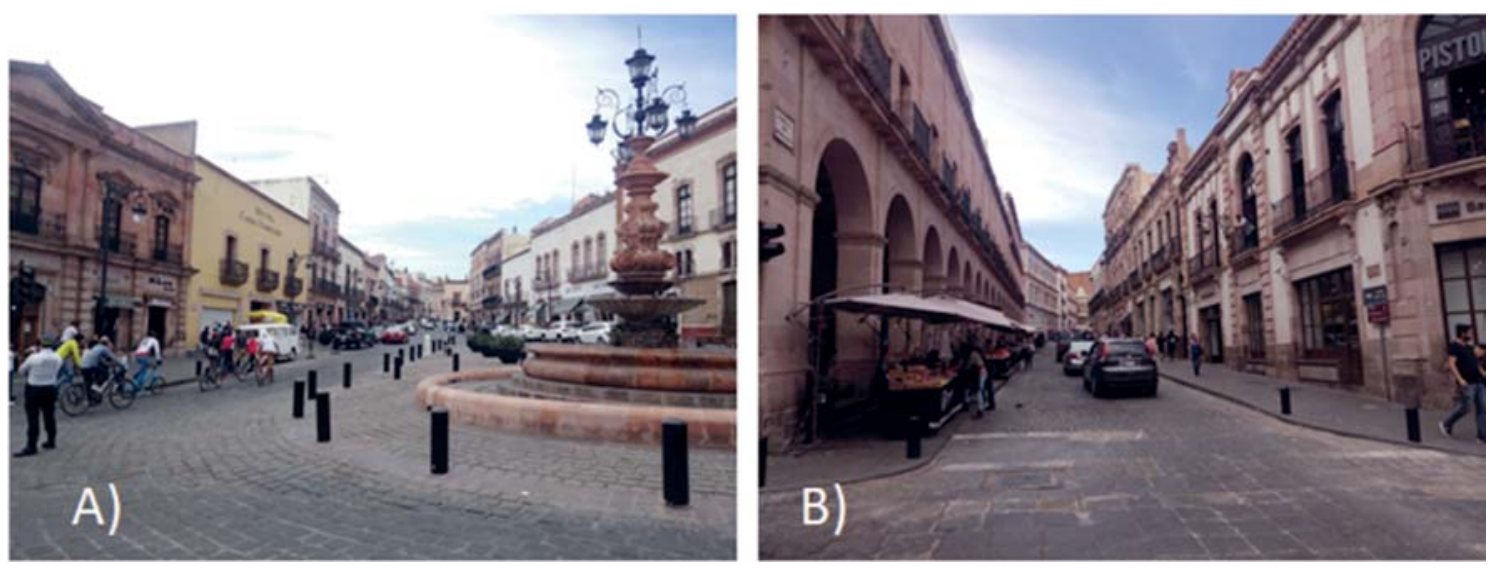

Nota. Archivo fotográfico personal, marzo 2019.

\section{Figura 4}

Vista panorámica del Centro Histórico de Zacatecas
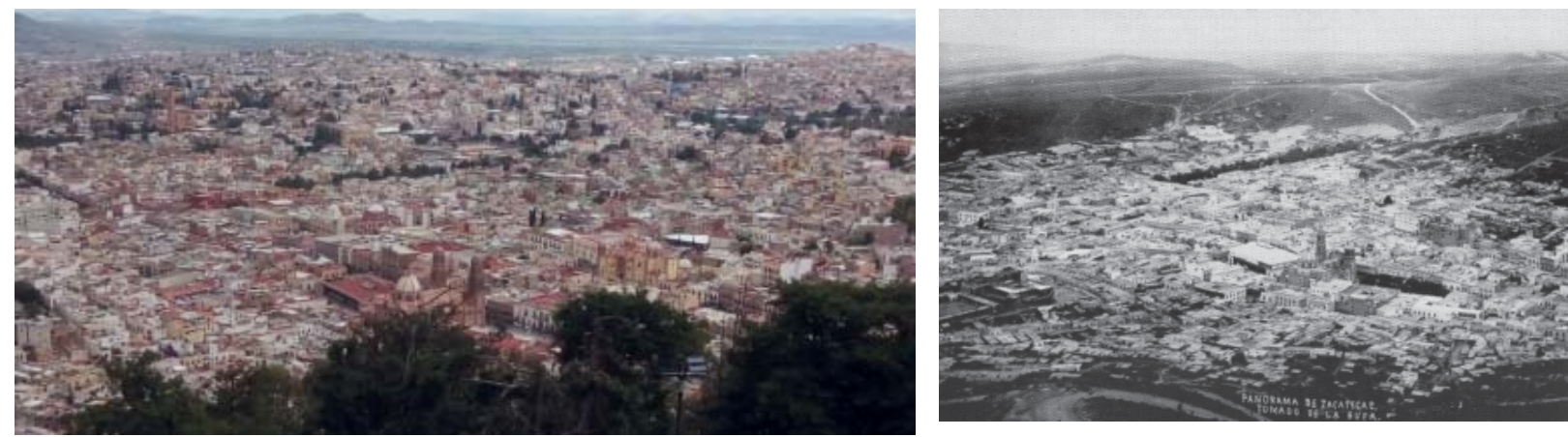

Nota. Fotografía izquierda, archivo fotográfico personal, marzo 2016. Fotografía derecha, autor no identificado. Panorama de Zacatecas tomado de la Bufa, 1896. 24.4 x 17.7, albúmina. Tomada de Infante (2006).

Sin embargo, conviene hacer la distinción que el proyecto turístico del Centro Histórico de Zacatecas como Patrimonio Cultural de la Humanidad está más orientado al aprovechamiento de la renta turística.

Por lo tanto, se desprenden algunas reflexiones en relación con la valorización del patrimonio cultural en los centros históricos:

- La valorización del patrimonio cultural está inmersa bajo la economía de enclave turístico, que da cuenta de una jerarquización y centralización de servicios turísticos, de espacios de inversión, quedando fuera los 
servicios y espacios destinados para la vida cotidiana de la población, por ejemplo: los servicios de salud, educación, deportes, etc.

- En el discurso del Estado, se crean políticas culturales que buscan legitimar el modelo de desarrollo imperante, donde destacan las prácticas extractivistas, explotadoras y de acumulación del capital proveniente de la práctica turística apoyada en el modelo nacional, todo esto en beneficio de algunos en el poder y de su posición como inversionistas.

- Esta dinámica generó un profundo impacto en la sociedad, ya que al verse desplazados de sus viviendas, precarizadas sus condiciones laborales, condicionada su libertad de tránsito por la ciudad y su disfrute, además de imponer nuevas transformaciones al patrimonio que creía propio, la dinámica por perder sus espacios públicos en beneficio del turista o del visitante, propician una suerte de enfado hacia el Estado, generando así movimientos que defienden que ya no se explote o transforme más el patrimonio cultural, el espacio público y las prácticas cotidianas.

\section{Transformación del Centro Histórico de Zacatecas}

Todo el equipamiento e infraestructura turística y comercial se concentra en la avenida Hidalgo (Figura 5) donde se localizan la Catedral y otros templos ubicados en el primer cuadro de la ciudad; de ahí que los principales servicios turísticos y el comercio se encuentren alrededor de los atractivos culturales de la ciudad, que al comparar con el registro de los inmuebles registrados como patrimonio de arquitectura relevante, tradicional, del siglo XX y de valor ambiental (Figura 6), resulta que en la parte central se concentran en mayor número de inmuebles dedicados a los principales servicios, de atractivos, de arquitectura relevante en comparación con las viviendas poco habitadas.

\section{Figura 5}

Avenida Hidalgo del Centro Histórico de Zacatecas

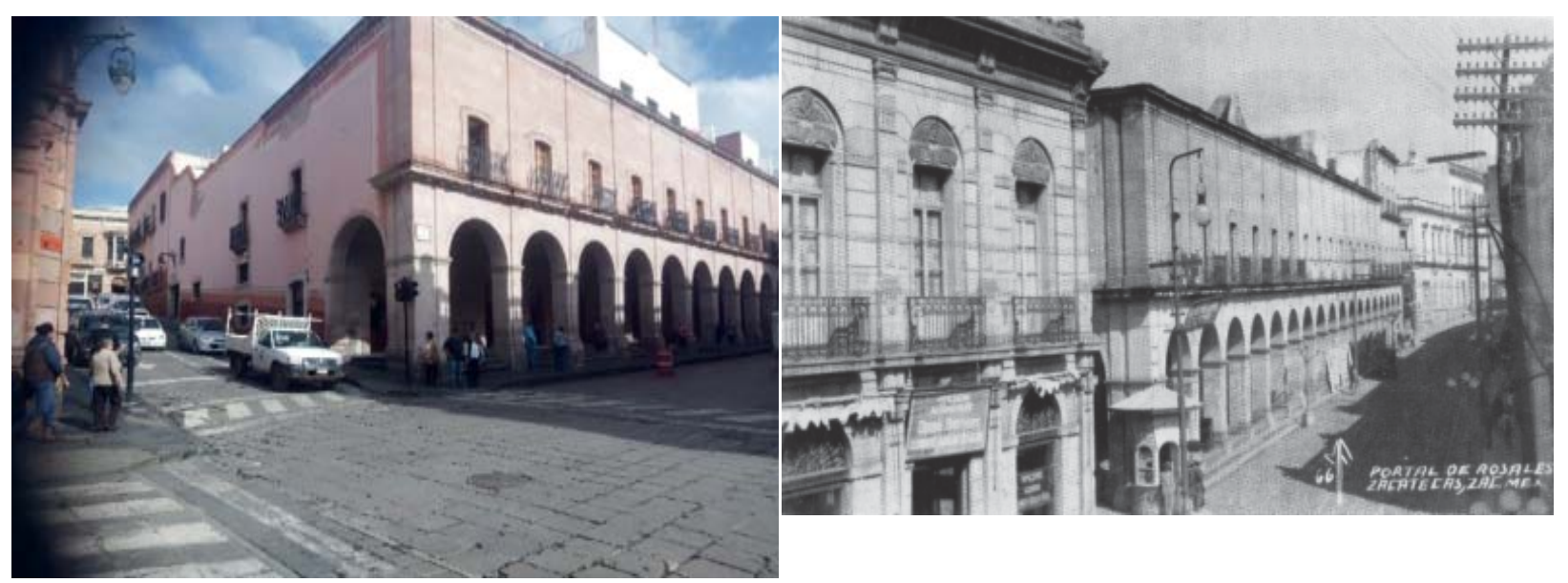

Nota. (Fotografía izquierda) Archivo fotográfico personal, marzo, 2016. (Fotografía derecha) Autor no identificado. Fot. México Fotográfico. Portal de Rosales, ca. 1940. 13.3 x 8.5, plata-gelatina. Tomada de Infante (2006). 


\section{Figura 6}

Relación del patrimonio cultural en términos de arquitectura
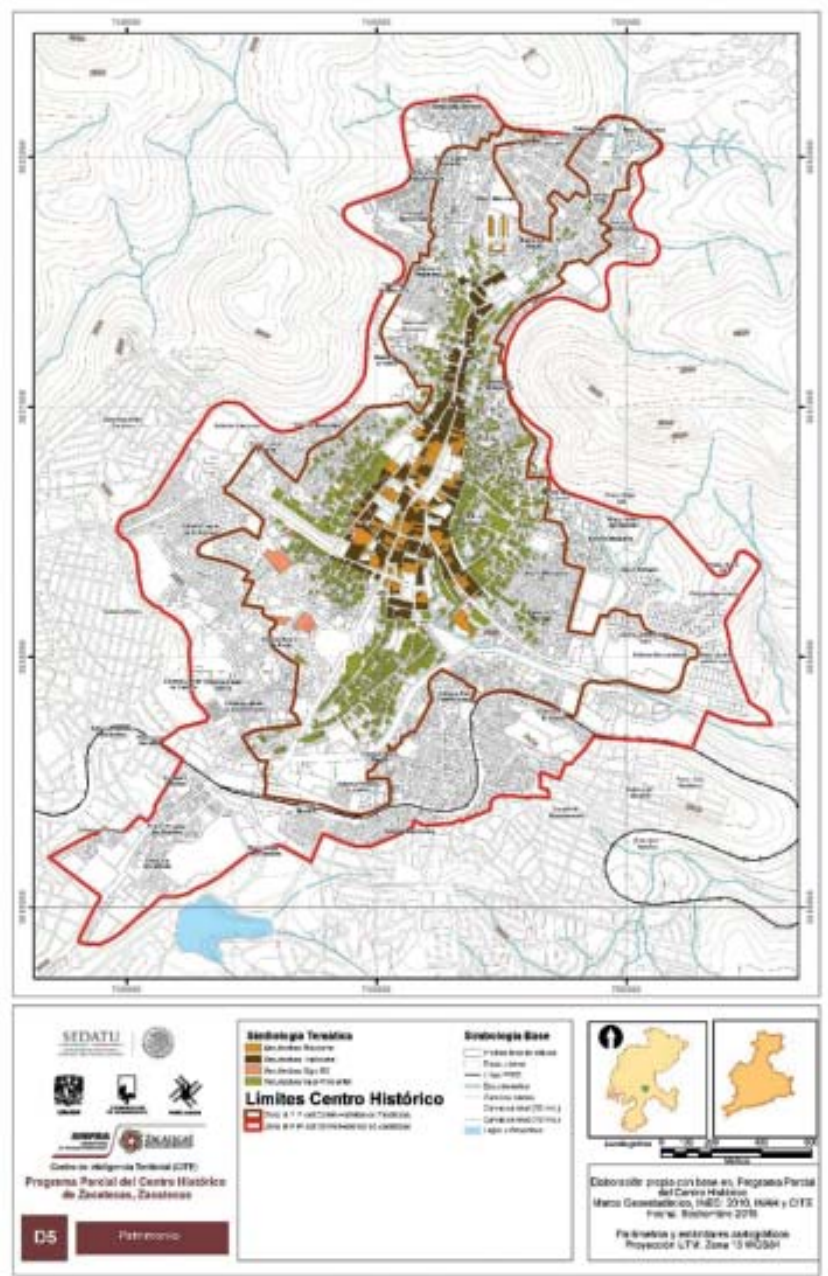

Nota. Secretaría de Desarrollo Agrario, Territorial y Urbano (SEDATU). Zacatecas 2019. http://cit.zacatecas.gob.mx/documentos/PPCH\%20ZACATECAS/PPCH\%2OPDF/ D5\%20Zacatecas\%20Patrimonio.pdf

\section{Alternativas frente a la valorización y rentabilidad: el derecho a la ciudad}

Como modalidad de resistencia frente a la rentabilización del patrimonio se puede proponer el modelo alternativo conocido como Derecho a la Ciudad, propuesta en la que es de interés abundar sobre el papel de los ciudadanos y los consumidores. Este modelo es conocido teóricamente como movimientos ciudadanos, resistencias y/o insurgencias. Una de las resistencias es conocida como la lucha contra la renta monopólica que implica entre otras cosas «como mínimo, resistencia a la idea de que la autenticidad, creatividad y originalidad son un producto exclusivo de la geografía histórica burguesa, y no de la clase obrera, los campesinos u otras clases no capitalistas» (Harvey, 2013, p. 165). 
Los movimientos y resistencias hacen que los habitantes busquen la manera de contraponerse a la renta monopólica o busquen beneficiarse de ella, por lo cual se desprende una noción del derecho a la ciudad.

No es un derecho únicamente individual, sino un derecho colectivo concentrado. Incluye no solo a los trabajadores de la construcción, sino también a todos aquellos que facilitan la reproducción de la vida cotidiana: Los cuidadores y maestros, los reparadores del alcantarillado y el suburbano, los fontaneros y electricistas, los que levantan andamios y hacen funcionar las grúas, los trabajadores de los hospitales y los conductores de camiones, autobuses y taxis, los cocineros, camareros y animadores de los restaurantes y salas de fiesta, los oficinistas de los bancos y los administradores de la ciudad. (Harvey 2013, pp. 201-202)

El derecho a la ciudad se entiende como «una respuesta democrática que integra a la vez los derechos de los ciudadanos y los criterios urbanísticos que hacen posible su ejercicio, en especial la concepción del espacio público» (Borja, 2012, p. 214), un aporte de esta visión es ubicar el papel de la democracia para observar las dimensiones políticas, culturales y sociales. El espacio público es entendido como espacio de uso colectivo, en este se reflejan los conflictos, las aspiraciones, las políticas públicas a raíz de iniciativas privadas, se observan las dinámicas urbanas actuales, también deben funcionar servicios suficientes para la demanda de los que habitan en el lugar, no debe haber marginalidad porque conlleva a la criminalidad (Borja, 2012).

En la actualidad, se ha generado la pérdida de los espacios públicos en los centros históricos por contener la «etiqueta» de los nombramientos internacional o nacional (Hernández, 2009) por lo que algunos proponen crear un movimiento de la sociedad civil en la que se involucre en la gobernanza y gestión de la ciudad (Sepúlveda, 2017), y por lo tanto, de su patrimonio. El turismo a la larga ha creado conflictos entre sus anfitriones y sus visitantes, por un lado, se crean resistencias por querer recuperar la ciudad que recuerdan, sin tanta invasión extranjera ni franquicias que dan otra dinámica de consumo y orden en las formas más cotidianas de los habitantes.

\section{Conclusiones}

El proyecto turístico cultural está insertado en las formas rentistas de la valorización del patrimonio cultural, que en el caso de Zacatecas es un fenómeno que ha dado pie a las inercias del modelo neoliberal, y en concreto, a la acumulación por desposesión. El turismo en Zacatecas pretende ser un proyecto que surge desde el gobierno, con políticas públicas donde se incluye una serie de elementos político-económicos-sociales que optan por el aprovechamiento del espacio y la declaratoria del Patrimonio Cultural de la Humanidad.

Sin embargo, la notoria falta de inclusión hacia todos los pobladores y públicos potenciales hacen que se cuestione la operatividad de dicho proyecto, ya que ha venido gestionando beneficios mercantiles para una oligarquía, ya sea que se trate de la cultura patrocinada (empresarios) y se orienta el consumo elitista de ciertos productos posicionados al alcance de una zona de consumo preferente.

La gestión del Estado en el proyecto turístico, más que beneficiar a la población -como se dice en los discursos oficiales- con la derrama generada por los visitantes, no ha logrado consolidarse como mejora en las condiciones de vida, y por lo tanto, no es el sector que ayude al centro histórico ni en lo económico, ni en lo 
social ya que se ha generado desplazamiento y descontento de la población en general por la demarcación social que muestra la periferia en comparación al centro.

Las relaciones de poder desde los inicios del proyecto turístico cultural en Zacatecas han cambiado en cuanto a las formas de gestionarlo, con el paso de los años se observa cómo han cambian los intereses en el marco de la valorización del patrimonio cultural, de ser el repunte de inversión estatal con fines de conservación, se convierte en prácticas de inversión privadas para beneficiar los intereses empresariales.

Finalmente, se pueden encontrar alternativas de lucha para defender el patrimonio cultural y la ciudad histórica como parte de una comunidad. Se trata de organizar a la población que ha sido despojada de sus bienes comunes que se han mercantilizado, y por tanto, sus condiciones los han llevado a la precarización. 


\section{Referencias}

Bakewell, P. J. (1997). Minería y sociedad en el México colonial. Zacatecas (1546-1700). México: Fondo de Cultura Económica.

Benjamin, W. (1989). El arte en la era de la reproducibilidad técnica. Madrid: Itaca.

Borja, J. (2012). Revolución urbana y derechos ciudadanos: Claves para interpretar las contradicciones de la ciudad actual (tesis doctoral, Universitat de Barcelona). http://diposit.ub.edu/dspace/handle/2445/42013

Covarrubias, G. F. (Coord.). (2016). Programa parcial de desarrollo urbano del Centro Histórico de Zacatecas 2016-2040. http:// www.observatorio.gobiernoabiertozacatecas.org.mx/wp-content/uploads/2017/05/PPCH-Zacatecas-2016-2040-N.pdf

González, H. G. M. (2014). Circo sin pan: Regeneración y mercantilización en el Centro Histórico. http://estudiosdeldesarrollo.mx/ documentos/CircosinPan.pdf

González, R. M. (2005). Breve historia de Zacatecas. Artes de México, 34, 88.

Harvey, D. (2013). Ciudades rebeldes. Del derecho de la ciudad a la revolución urbana. Madrid: Akal.

Hernández, J. de J. (2009). Tequila: Centro mágico, pueblo tradicional ¿patrimonialización o privatización? Andamios. Revista de investigación social, 6(12), 41-67.

Infante, G. V. R. (Coord.) (2006). Colección Fotográfica Federico Sescosse Lejeune, Zacatecas, ISSSTEZAC.

Instituto Nacional de Estadística, Geografía e Informática (INEGI). Censo de Población y Vivienda 1980, 1990, $2000,2010$.

Marcús, J., Mansilla, J. A., Boy, M., Yanes, S. y Aricó, G. (2019). La ciudad mercancia. Turistificación, renovación urbana y políticas de control del espacio público (Ministerio de Cultura). Teseo Press Design.

Márquez, C. H. y Delgado, W. R. (2011). Signos vitales del capitalismo neoliberal: Imperialismo, crisis y transformación social. Estudios críticos del desarrollo, I(1), 11-50.

Márquez, C. H. (2018). Pensar la política desde la práctica. Falacias de la democracia y pertinencia de la emancipación. Estudios Críticos del Desarrollo, VIII(14), 171-226.

Marx, K. (1991). El capital (t. III, vol. 8). México: S. XXI editores.

Munk, R. (2011). Teoría crítica del desarrollo. En H. Veltmeyer, Herramientas para el cambio: Manual para los estudios críticos del desarrollo (pp. 73-77). CIDES-UMSA, Oxfam.

Programa Parcial del Centro Histórico. (2016). Densidad de vivienda. En A9 (SEDATU). Centro Histórico Zacatecas. http:// cit.zacatecas.gob.mx/index.php/programas-parciales-de-desarrollo-urbano-y-centro-historico/.

Sepúlveda, S. (2017). Estado del arte sobre Centros Históricos en México. En Ciudades y Centros Históricos. Los retos de la vivienda y la habitabilidad (vol. I, p. 180). https://www.researchgate.net/publication/316066851_Estado_del_arte_sobre_Centros _Historicos_en_Mexico

UNESCO. (s. f.). Patrimonio de la Humanidad. http://whc.unesco.org/en/list/676/

\footnotetext{
Mariana Rubí Raygoza Castro

Doctorante en la Unidad Académica en Estudios del Desarrollo de la Universidad Autónoma de Zacatecas (UAZ), docente-investigadora de la Licenciatura en Turismo de la UAZ desde hace 11 años, realizó estudios de maestría en Filosofía en la UAZ, Licenciatura en Antropología con especialidad en Arqueología UAZ y Licenciatura en Filosofía UAZ. Produjo publicaciones en memorias de los Congresos de Ciencias Sociales de la UAZ titulados: El turismo y el patrimonio cultural frente a las dinámicas del capital rentista (2018) ISBN: 978-607-9455-59-0, El laberinto de la identidad mexicana (2016) ISBN: 978-607-9455-18-7, La sustentabilidad de los pueblos mágicos en Zacatecas (2013) ISBN: 978-607-8056-26-2. Colaboración en proyecto arqueológico del área maya EL Chechén, Campeche, México (2003-2005). Impartió distintos cursos en coordinación con la Secretaría de Turismo del estado de Zacatecas tales como: Historia y Turismo de Zacatecas (2016), Informadores turísticos (2014), Prácticas Sustentables en el Sector Turístico (2013), además de diversos módulos en los Diplomados para Guías de Turistas Especializados en los Municipios del Teúl de González Ortega, Jerez de García Salinas, Zacatecas y Sombrerete, todos en el estado de Zacatecas (2010-2013).

mrraigoza@gmail.com

ORCID: https://orcid.org/0000-0002-5880-9932
} 